\title{
Microporous Structures Having Phenylene Fin: Significance of Substituent Groups for Rotational Linkers in Coordination Polymers
}

Ryotaro Matsuda ${ }^{a, b *}$, Wataru Kosaka $^{c}$, Ryo Kitaura ${ }^{d,{ }^{\dagger}}$, Yoshiki Kubota ${ }^{e}$, Masaki Takata ${ }^{b, f}$, Susumu Kitagawa $^{a, b, d *}$

Institute for Integrated Cell-Material Sciences, Kyoto University, Nishikyo-ku, Katsura, Kyoto 6158510, Japan.

${ }^{\mathrm{b}}$ Harima Institute, RIKEN SPring-8 Center, Sayo-gun, Hyogo 679-5148, Japan

${ }^{\mathrm{c} N a t u r a l ~ S c i e n c e ~ a n d ~ T e c h n o l o g y, ~ K a n a z a w a ~ U n i v e r s i t y, ~ K a k u m a-m a c h i, ~ K a n a z a w a ~ 920-1192, ~ J a p a n . ~}$

${ }^{\mathrm{d} D e p a r t m e n t ~ o f ~ S y n t h e t i c ~ C h e m i s t r y ~ a n d ~ B i o l o g i c a l ~ C h e m i s t r y, ~ G r a d u a t e ~ S c h o o l ~ o f ~ E n g i n e e r i n g, ~ K y o t o ~}$ University, Katsura, Kyoto 615-8510, Japan

${ }^{\mathrm{e}}$ Department of Physical Science, Graduate School of Science, Osaka Prefecture University, Sakai, Osaka 599-8531, Japan

fJapan Synchrotron Radiation Research Institute, Sayo-gun, Hyogo 679-5198, Japan.

*Corresponding author: RM and SK, Institute for Integrated Cell-Material Sciences, Kyoto University, Nishikyo-ku, Katsura, Kyoto 615-8510, Japan, Tel and Fax: +81-75-383-2103. Email:ryotaro.matsuda@gmail.com or kitagawa@icems.kyoto-u.ac.jp

${ }^{\dagger}$ Current address: Department of Chemistry, Nagoya University, Nagoya 464-8602, Japan 


\section{ABSTRACT}

Microporous coordination polymers having various shaped apertures were synthesized and crystallographically characterized using substituted terephthalate ligands. The substituents exert a notable influence on the channel size and shape depending on the orientations and disordering of the phenylene units such as a fin. This is a new aspect of porous coordination polymers, which would provide important information for a precise design of the micropore.

\section{Keywords}

Porous Coordination polymers; Metal-organic frameworks; Adsorption; Micropore 


\section{Introduction}

A new class of microporous materials known as porous coordination polymers that are constructed from metal ions and organic bridging ligands, has recently attracted a great deal of attention, [1-8] because of wide potential application ranging from gas storage, [9-16] molecular recognition and separation, [17-27] and heterogeneous catalysis[28-30] as multifunctional crystalline materials.[31-35] Now, they are gaining an important position in porous materials and adding a new category to a conventional classification. One of the advantages of microporous coordination polymers is highly designable framework in terms of pore shapes and surface property; even in topologically similar frameworks, sophisticatedly functionalized building units (i.e. organic ligands with functional groups) could provide a variety of porous properties. In these two decades, a large number of coordination polymers have been synthesized, most of which contain organic linkers having a fused hydrocarbon or heterocyclic rings for the sake of framework rigidity, affording a regular well-defined structures. Because the size of micropore is comparable to that of linkers and guest molecules, even a slight modification of the linker would impact on the sorption behavior of guest molecules. In a sense, size and shape of substituent group have important effect more than we expected. However, to date are sparse reports on analysis and examination of channel surfaces for microporous coordination polymers, where linkers are modified by substituents with the retention of topology. This is ascribed to the difficulty in systematic work that the crystal structure determination and examination of porous properties are simultaneously performed for all the compounds, whose linkers are systematically modified by substituent groups.

Recently, a series of 3-D grid-type frameworks have been constructed from M(II)/dicarboxylate/pillar ligand (where $\mathrm{M}=\mathrm{Cu}(\mathrm{II})$ or $\mathrm{Zn}(\mathrm{II})$, pillar ligand = 1,4-diazabicyclo[2.2.2]octane (dabco), 4,4'bipyridine or ligands with bis(4-pyridyl) group), which exhibit a high gas storage capacity. [13, 21, 3667] These compounds have a Jungle-gym-Analogue Structure, hereafter, this family is denoted as JAST, rationally obtained using various dicarboxylate building units. To gain a better understanding of chemical modification, namely substituent effect, on pore walls, and to establish guidelines in the 
design and synthesis of microporous coordination polymers, we focus on the influence of the introduction of substituents in linking ligands both on size and shape of the channel structures and on sorption properties (Scheme 1). 


\section{Experimental Section}

\section{Syntheses}

2,3-Difluoro-1,4-benzenedicarboxylic acid (H2DFBDC): To 2,3-difluorobenzoic acid (12.0 g, $76.1 \mathrm{mmol})$ in anhydrous tetrahydrofuran (THF) $(230 \mathrm{~mL})$ was added $1.6 \mathrm{M}$-buthyllithium in hexane $(110 \mathrm{~mL}, 176 \mathrm{mmol})$ at $-78{ }^{\circ} \mathrm{C}$. After stirring 2 hour at $-78{ }^{\circ} \mathrm{C}$, excess dry ice was added then the temperature was gradually allowed to rise to room temperature. The suspension was stirred for 1 hour. Following acidification with $1 \mathrm{~N} \mathrm{HCl}$ solution $(200 \mathrm{ml})$ at $0{ }^{\circ} \mathrm{C}$, the organic phase was extracted with diethyl ether. The extracts were washed with water and dried over $\mathrm{Na}_{2} \mathrm{SO}_{4}$ then evaporated to dryness under reduced pressure (3.65 g, $18.1 \mathrm{mmol}, 24 \%$ yield). Mass: m/e (\%) $203[\mathrm{M}+1 \cdot,(88)], 185$ [M $\mathrm{OH},(100)], 158[\mathrm{M}-\mathrm{COOH},(6)]$.

2,3-Dimethoxy-1,4-benzenedicarboxylic acid (H2DMBDC): To 1,2-dimethoxybenzene (1.91 $\mathrm{mL}, 15.0 \mathrm{mmol}$ ) and $\mathrm{N}, \mathrm{N}, \mathrm{N}^{\prime}, \mathrm{N}^{\prime}$-tetramethylethylenediamine (TMEDA) (36.6 mL, $\left.60.0 \mathrm{mmol}\right)$ in

anhydrous diethyl ether $\left(\mathrm{Et}_{2} \mathrm{O}\right)(100 \mathrm{~mL})$ was added dropwise $1.6 \mathrm{M}$ n-buthyllithium in hexane (10.6 $\mathrm{mL}, 70.0 \mathrm{mmol}$ ) at $-78{ }^{\circ} \mathrm{C}$. After stirring 2.5 hour at $-78{ }^{\circ} \mathrm{C}$, the temperature was allowed to rise to room temperature then the suspension was stirred for 3 days. After the temperature was allowed to decrease to $-78{ }^{\circ} \mathrm{C}$, excess dry ice was added then the temperature was gradually allowed to rise to room temperature and the mixture was stirred at room temperature. The Following acidification with $1 \mathrm{~N}$ $\mathrm{HCl}$ solution $(100 \mathrm{ml})$ at $0{ }^{\circ} \mathrm{C}$, the organic phase was extracted with diethyl ether. The extracts were washed with water and dried over $\mathrm{Na}_{2} \mathrm{SO}_{4}$ then evaporated to dryness under reduced pressure $(583 \mathrm{mg}$, $2.58 \mathrm{mmol}, 17 \%$ yield). ${ }^{1} \mathrm{H}-\mathrm{NMR}\left(\mathrm{CD}_{3} \mathrm{OD}\right): \delta=7.41(\mathrm{~s}, 2 \mathrm{H}), \delta=3.83(\mathrm{~s}, 6 \mathrm{H})$. Mass: m/e (\%) $226[\mathrm{M} \bullet+$, (100)], $151\left[\mathrm{M}-\mathrm{OCH}_{3}-\mathrm{COO},(68)\right], 134\left[\mathrm{M}-(\mathrm{COOH})_{2},(25)\right]$.

JAST-1 , -2, -3 -4 and -5: JAST-1 was prepared by using the literature[36, 37] method, with some modifications. A solution of $\mathrm{Cu}(\mathrm{HCOO})_{2} \cdot 4 \mathrm{H}_{2} \mathrm{O}(0.21 \mathrm{~g}, 1.00 \mathrm{mmol})$ dissolved in methanol (100 $\mathrm{mL})$ and formic acid $(2 \mathrm{~mL})$ was slowly added to the methanol solution $(100 \mathrm{~mL})$ containing 1,4benzenedicarboxylic acid $(0.21 \mathrm{~g}, 1.00 \mathrm{mmol})$ at room temperature. After stirring for 3 day, the blue resultant precipitate were separated by centrifugation from mother liquor then transferred to stainless sealed Teflon reaction vessel. A toluene/methanol (1/1) solution of 1,4-diazabicyclo[2,2,2]octane (dabco) was added to the vessel. After reaction at $413 \mathrm{~K}$ for 12 hour, the resultant yellow-green precipitate was filtered, washed with methanol and dried under reduced pressure. JAST-2, $\mathbf{- 3}, \mathbf{- 4}$ and -5 was prepared in the same way as described for JAST-1 by using $\mathrm{H}_{2}$ DFBDC, $\mathrm{H}_{2} \mathrm{NDC}_{2} \mathrm{H}_{2}$ TFBDC and $\mathrm{H}_{2} \mathrm{DMBDC}$ instead of $\mathrm{H}_{2} \mathrm{BDC}$, respectively.

\section{Adsorption Measurements}

The adsorption isotherms nitrogen at $77 \mathrm{~K}$ were measured with BELSORP18 volumetric adsorption equipment from Bel Japan. Nitrogen gas of high purity $(99.9999 \%)$ were used. Prior to the adsorption 
measurements, All samples were obtained by treating under reduced pressure $\left(<10^{-2} \mathrm{~Pa}\right)$ at $393 \mathrm{~K}$ for more than $10 \mathrm{~h}$.

\section{Dubinin-Radushkevich (DR) analysis[68]}

The DR equation is given by

$$
\ln W=\ln W_{0}-\left(\mathrm{A} / \beta E_{0}\right)^{2}
$$

where $W$ and $W_{0}$ are the amount of adsorption at a relative pressure $\left(P / P_{0}\right)$ and the saturated amount of adsorption, respectively, $E_{0}$ is a characteristic adsorption energy, and the parameter $A$ is Polanyi's adsorption potential, shown in equation (2).

$$
A=R \operatorname{Tln}\left(P_{0} / P\right)
$$

The parameter $\beta$ is the affinity coefficient, and is related to the adsorbate-adsorbent interaction. The DR plots showed a linear relationship existed at higher $P / P_{0}$ region, from which, the micropore volume and the value of $\beta E_{0}$ were obtained. The micropore volume, $V m$, was calculated from the value of $W_{0}$ and the density of the adsorbate by assuming that the molecules were adsorbed as a liquid, $0.807 \mathrm{~g} / \mathrm{cm}^{3}$. The value of $\beta E_{0}$ allows for the calculation of the isosteric heat of adsorption, $q_{s t, \Phi=1 / e}$, at the fractional filling of 1/e using equation (3) where $\Delta H_{v}$ is the heat of vaporization of the bulk liquid. The value for $\Delta H_{v}$ for nitrogen at $77 \mathrm{~K}$ is $5.58 \mathrm{~kJ} \mathrm{~mol}^{-1}$.

$$
q_{s t, \Phi=1 / e}=\Delta H_{v}+\beta E_{0}
$$

\section{X-ray Powder Diffraction Experiment}

The powder samples for each compound were sealed in a silica glass capillary ( $0.4 \mathrm{~mm}$ inside diameter). XRPD pattern with good counting statistics was measured by the synchrotron radiation XRPD experiment with the large Debye-Scherrer camera and imaging plate as detectors on the BL02B2 beam line[69] and BL44B2[70] at the Super Photon Ring (SPring-8, Hyogo, Japan). All the XRPD patterns are obtained with a $0.01^{\circ}$ step.

\section{Structure Determination}

The structure determinations were performed using a high brilliance synchrotron powder diffraction data. The patterns were indexed by using the indexing program DICVOL91.[71] A good quality unit cell refinement was obtained by using the structure-less Le Bail fitting method.[72] The peak shape was modeled by a Split-Pearson function. The structure refinement was performed by Rietveld method with RIETAN software.[73, 74] Soft constraints about bond angles and bond distances was adapted throughout the refinement. Hydrogen atoms were placed at calculated position and their parameters were not refined. The result of the Rietveld refinement are shown in Figures S1-S4. The crystallographic data for JAST compounds are summarized in Tables 1 and 2. 


\section{Results and Discussion}

\section{Structural aspect of JAST compounds}

We synthesized five JAST compounds, [Cu2(BDC) ${ }_{2}$ dabco] (JAST-1),[36] [Cu2(DFBDC) $\left.)_{2} \mathrm{dabco}\right]$
(JAST-2),
[Cu2(TFBDC) $)_{2}$ dabco]
(JAST-3),[37]
$\left[\mathrm{Cu}_{2}(\mathrm{NDC})_{2} \mathrm{dabco}\right]$
(JAST-4),[40]

$\left[\mathrm{Cu}_{2}\right.$ (DMBDC) ${ }_{2}$ dabco] (JAST-5)[40] (where BDC $=$ 1,4-benzenedicarboxylate; DFBDC $=2,3$ Difluoro-1,4-benzenedicarboxylate; TFBDC $=2,3,5,6$-Tetrafluoro-1,4-benzenedicarboxylate; NDC = 1,4-naphthalenedicarboxylate; DMBDC $=2,3$-Dimethoxy-1,4-benzenedicarboxylate; dabco $=1,4$ diazabicyclo[2.2.2]octane) (Scheme 2).

The crystal structures of the JAST-1, -2, -3, -4, and $\mathbf{- 5}$ at room temperature were determined from synchrotron XRPD measurements and Rietveld analysis (Table 1). All crystals were assigned to be same space group, P4/mmm (\#123). In all the JAST compounds, the building units consisting of a paddle wheel type copper(II) dimer are linked by the dicarboxylate ligands, resulting in a regular square grid type layer in the $a b$ plane. The layers are linked by disordered dabco acting as a pillar whose nitrogen atoms are coordinated to the copper atoms from the apical position.[75] Consequently, the $\mathrm{Cu}(\mathrm{II})$ units locate on the apices of tetragonal unit cell, affording a 3D pillared layer open framework (jungle-gym structure), shown in Figure 1. The unit cells of all the JAST compounds are nearly equal to each other, which are estimated to be $10.8 \times 10.8 \times 9.6 \AA^{3}$.

Crystallographic structures for all the compounds show three channels along the $a, b$, and $c$ axes. The shape and size of channels are determined by the phenylene planes acting as a fin, which is best described by the two parameters; one is the dihedral angle $(\theta)$ between the phenylene plane of the BDC family and the $a c$ (or $b c$ ) plane. The other parameter is that as to whether BDC moiety is symmetrical (where $\mathrm{R}^{1}=\mathrm{R}^{2}$ in Scheme 3) or asymmetrical (where $\mathrm{R}^{1} \neq \mathrm{R}^{2}$ in Scheme 3) with respect to the $C_{2}$ axis that passes from 1 to 4 carbon position of the BDC moiety. JAST compounds can be classified by the parameters, which are summarized in Table 2, and each category has characteristic features of the apertures in the channels.

JAST-1 and -2 have a simple channel system because of the $\theta$ value of $0^{\circ}$, where the phenylene planes sit parallel to the $c$-axis, and therefore, the channel along the $c$ axis has a flat and smooth surface with the dimensions in aperture $\left(\sigma_{c}\right)$ of $7.9 \times 7.9 \AA^{2}$.[76] On the other hand, the phenylene planes of JAST-3, -4 and -5 incline against the $c$ axis with the $\theta$ values of $36^{\circ}, 49^{\circ}$ and $36^{\circ}$, respectively, giving rise to a substantial surface corrugation of the channels. This inclination is associated with repulsion between the substituent groups of BDC and $\mathrm{O}$ atom in carboxylates. In addition, the phenylene planes undergo a disorder with the two different orientations, from which several apertures are created; one of

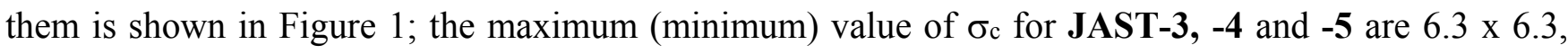
5.7 x 5.7 and 6.4 × $6.4 \AA^{2}\left(5.3\right.$ × 5.3, 2.4 x 2.4 and 2.5 × $\left.2.5 \AA^{2}\right)$, respectively. 
While all the compounds have the same width $(w), 4.7 \AA$, of the apertures of $\sigma_{\mathrm{b}}\left(\sigma_{\mathrm{a}}\right)$, the height (h) for each compound is different from each other depending on the parameters as mentioned above (Scheme 3). Figures 2 show the cross-section of apertures of $\sigma_{b}\left(\sigma_{a}\right)$ along the $a(b)$ axis and the value of $h$. Whereas the value of $h$ for JAST-1 is single value of $3.4 \AA$, those for JAST-2, -3, -4 and -5 range from 2.6 to $3.3,3.3$ to $4.4,1.5$ to 4.9 and 0 to $4.4 \AA$, respectively. Consequently, JAST-1 has two kinds of straight wall channels, while JAST-2 has a straight wall channel along the $c$ axis and two corrugated surface channels along the $a$ or $b$ axis, and JAST-3 -4 and -5 have a variety of corrugated channels.

On the basis, we can classify these compounds into two subgroups by considering the size of nitrogen as a guest molecule. Since the kinetic diameter of nitrogen is $3.64 \AA$, [77] the values for $\sigma_{b}\left(\sigma_{a}\right)$ of JAST-1 and -2 are so small to pass the molecules that we regard them as compounds with a single channel along the $c$ axis. On the other hand, the apertures of $\sigma_{b}\left(\sigma_{a}\right)$ for JAST-3, $\mathbf{- 4}$ and $\mathbf{- 5}$ are large enough for nitrogen to pass it, therefore the nitrogen molecules could diffuse three-dimensionally. Accordingly, JAST-1 and -2 provide the porous structures based on uniform 1-dimensional channel whereas JAST-3, -4 and -5 afford those with inter-connected 3-dimensional channel with various sizes and shapes as far as nitrogen molecule. Irrespective of the retention of the framework topology, the metrics and shapes of the channel are readily regulated by simple introduction of substituent groups.

\section{Sorption Properties}

The adsorption isotherms of nitrogen for the JAST compounds (except JAST-3 due to its less stability) were measured at $77 \mathrm{~K}$, shown in Figure 3. All the compounds exhibit a typical Type I adsorption isotherm as expected from the crystal structures. Dubinin-Radushkevich (DR) analysis affords the saturated amount of adsorption $\left(W_{0}\right)$, the micropore volume $(V m)$, and the value of $\beta E_{0}$, where $E_{0}$ and $\beta$ are characteristic adsorption energy and the affinity coefficient. The $\beta E_{0}$ provides the isosteric heat of adsorption, $q_{s t, \Phi=1 / e}$ at the fractional filling at 1/e. The micoropore and thermodynamic parameters of JAST compounds are summarized in Table 3.

The isotherms well reflects the effect of the substituents characteristic of the pressure regions; 1 ) region I at the low pressure, 2) region II at the middle pressure, and 3) region III at the high pressure, which gives a saturation of $\mathrm{N}_{2}$ adsorption for all the compounds. At region $\mathrm{I}$, the adsorption isotherms plotted against the logarithmic relative pressure shown in Figure 4 clearly show the difference of the profiles and onset pressures of the adsorption. Because the adsorption potential is expressed as a function of the relative pressure of adsorbate in the Polanyi's equation which is given by the Equation 2, the difference of onset pressures indicates the difference of the potential at initial adsorption. In the case of micropore $(0.35 \AA<\mathrm{d}<20 \AA)$, it has been established that the interaction between adsorbates and pore walls becomes stronger with decrease in the pore size because of a close contact, resulting from the overlapping of the attractive potential from the surfaces of the channel.[78] The onset pressures in the 
isotherm of JAST-1 and -2 are appreciably higher than those of JAST-4 and -5, which is consistent with the pore size order that JAST-1 and -2 have larger pore than those of JAST-4 and -5 with respect to along the $c$-axis. In addition to this, a little lower onset pressure of JAST-4 can be recognized as compared to JAST-5, which is also consistent with the order of the pore size. Consequently, the initial onset adsorption pressure follows the order of the metrics of the channel.

Polar groups on surfaces would give rise to an additional interaction with guest molecule,[79] however in this case, the difference in the on-set pressures for JAST-1 and -2 is not recognized as well as the values of $q_{s t, \Phi=1 / e}$. Accordingly, the polar effect is not detectable as far as nitrogen adsorption on JAST compounds.

The adsorption profile at the region II reflects the pore size and shape distribution, herein that of channels. The adsorption profiles for JAST-1 and -2 show a steep increase in the pressure region whereas those for JAST-4 and -5 have a gentle slope. The adsorption potential distribution of a porous solid can be characterized by the differential distribution of the adsorbed amount with respect to the adsorption potential, and the adsorption distribution of the adsorption energy reflects structural heterogeneity.[80] Non-normalized adsorption potential distributions shown in Figure 5 were estimated using Equation 2. Both JAST-1 and -2 exhibit a single peak distribution in the range of the adsorption potential $(A)$ between 5 and $7 \mathrm{~kJ} / \mathrm{mol}$ while the curves for JAST-4 and $\mathbf{- 5}$ possess a broader peak(s) located at between 5 and $8 \mathrm{~kJ} / \mathrm{mol}$, indicating heterogeneous pores for nitrogen. These results are consistent with the structural aspects for nitrogen as guests that JAST-1 and -2 have a uniform 1Dchannel and JAST-4 and -5 have corrugated 3D-channels with various size apertures. In the region III, the rotational motions of ligand molecule would be much influenced by the adsorbed guest molecules. In particular, JAST-5 has large freedom of not only phenylene rings but also methoxy groups in the lower pressure region, however, in the higher pressure region III, the dynamic motion would be strongly hindered by the guest molecules adsorbed, which should cause repulsive interaction between host and guest, and is resulting in the lower heat of adsorption of JAST-5. 


\section{Conclusion}

Herein, we examined the effect of a ligand modification on the channel structures with retention of the square grid framework topology and nitrogen adsorption. The substituents exert a notable influence on the channel size and shape depending on the orientations and disordering of the phenylene units such as a fin. The modification of ligands with substituent groups can change not only the electrostatic nature of pore surface but also the channel dimensions of porous coordination polymers, which indicates that adsorption functions can be finely tuned by small substituent groups. Actually, the sorption pressures were tuned by the substituent groups in the four JAST compounds whereas they have the same network topology. This new aspect of porous coordination polymers provides useful information for understanding and design of microporous coordination polymers as adsorbent. 


\section{Acknowledgements}

The synchrotron radiation experiments were performed at the BL44B2 RIKEN beam line and BL02B2 beam line in the SPring-8. We would like to thank Prof. Dr. Tatsuo C. Kobayashi and Dr. Kenichi Kato for their experimental help at SPring-8. This work was supported by a The Exploratory Research for Advanced Technology (ERATO) research funding program "ERATO Kitagawa Integrated Pores Project" (No. 464) from Japan Science and Technology Agency (JST), and also by JSPS KAKENHI Grant Number 25620187, Grant-in-Aid for Challenging Exploratory Research. Supplementary Information for this article is available on the website of MMM. 


\section{References}

[1] H.-C. Zhou, J.R. Long, O.M. Yaghi, Chem. Rev., 112 (2012) 673-674.

[2] A.P. Cote, G.K.H. Shimizu, Coord. Chem. Rev., 245 (2003) 49-64.

[3] B. Moulton, M.J. Zaworotko, Chem. Rev., 101 (2001) 1629-1658.

[4] O.M. Yaghi, M. O'Keeffe, N.W. Ockwig, H.K. Chae, M. Eddaoudi, J. Kim, Nature, 423 (2003) 705714.

[5] S. Kitagawa, R. Kitaura, S.-i. Noro, Angew. Chem., Int. Ed., 43 (2004) 2334-23375.

[6] N.W. Ockwig, O. Delgado-Friedrichs, M. O'Keeffe, O.M. Yaghi, Acc. Chem. Res., 38 (2005) 176182.

[7] G. Ferey, C. Mellot-Draznieks, C. Serre, F. Millange, Acc. Chem. Res., 38 (2005) 217-225.

[8] S. Kitagawa, R. Matsuda, Coord. Chem. Rev., 251 (2007) 2490-2509.

[9] M.P. Suh, H.J. Park, T.K. Prasad, D.-W. Lim, Chem. Rev., 112 (2012) 782-835.

[10] S. Bureekaew, H. Sato, R. Matsuda, Y. Kubota, R. Hirose, J. Kim, K. Kato, M. Takata, S.

Kitagawa, Angew. Chem., Int. Ed., 49 (2010) 7660-7664.

[11] G. Ferey, M. Latroche, C. Serre, F. Millange, T. Loiseau, A. Percheron-Guegan, Chem. Commun., (2003) 2976-2977.

[12] D.V. Soldatov, I.L. Moudrakovski, C.I. Ratcliffe, R. Dutrisac, J.A. Ripmeester, Chem. Mater., 15 (2003) 4810-4818.

[13] K. Seki, W. Mori, Journal of Physical Chemistry B, 106 (2002) 1380-1385.

[14] H.K. Chae, D.Y. Siberio-Perez, J. Kim, Y. Go, M. Eddaoudi, A.J. Matzger, M. O'Keeffe, O.M. Yaghi, Nature, 427 (2004) 523-527.

[15] X. Zhao, B. Xiao, A.J. Fletcher, K.M. Thomas, D. Bradshaw, M.J. Rosseinsky, Science, 306 (2004) 1012-1015.

[16] M. Kondo, T. Yoshitomi, K. Seki, H. Matsuzaka, S. Kitagawa, Angew. Chem., Int. Ed., 36 (1997) 1725-1727.

[17] H. Wu, Q. Gong, D.H. Olson, J. Li, Chem. Rev., 112 (2012) 836-868.

[18] K. Sumida, D.L. Rogow, J.A. Mason, T.M. McDonald, E.D. Bloch, Z.R. Herm, T.-H. Bae, J.R. Long, Chem. Rev., 112 (2012) 724-781.

[19] J.-R. Li, J. Sculley, H.-C. Zhou, Chem. Rev., 112 (2012) 869-932.

[20] J. Seo, R. Matsuda, H. Sakamoto, C. Bonneau, S. Kitagawa, J. Am. Chem. Soc., 131 (2009) 1279212800 .

[21] J. Seo, C. Bonneau, R. Matsuda, M. Takata, S. Kitagawa, J. Am. Chem. Soc., 133 (2011) 90059013.

[22] M.E. Kosal, J.-H. Chou, S.R. Wilson, K.S. Suslick, Nat. Mater.., 1 (2002) 118-121.

[23] B. Kesanli, W. Lin, Coord. Chem. Rev., 246 (2003) 305-326. 
[24] R. Matsuda, R. Kitaura, S. Kitagawa, Y. Kubota, T.C. Kobayashi, S. Horike, M. Takata, J. Am. Chem. Soc., 43 (2004) 14063-14070.

[25] R. Matsuda, R. Kitaura, S. Kitagawa, Y. Kubota, R.V. Belosludov, T.C. Kobayashi, H. Sakamoto, T. Chiba, M. Takata, Y. Kawazoe, Y. Mita, Nature, 436 (2005) 238-241.

[26] R. Matsuda, R. Kitaura, Y. Kubota, T.C. Kobayashi, M. Takata, S. Kitagawa, Microporous Mesoporous Mater., 129 (2010) 296-303.

[27] R. Matsuda, T. Tsujino, H. Sato, Y. Kubota, K. Morishige, M. Takata, S. Kitagawa, Chemical Sci., 1 (2010) 315-321.

[28] J.S. Seo, D. Whang, H. Lee, S.I. Jun, J. Oh, Y.J. Jeon, K. Kim, Nature, 404 (2000) 982-986.

[29] O. Ohmori, M. Fujita, Chem. Commun., (2004) 1586-1587.

[30] M. Yoon, R. Srirambalaji, K. Kim, Chem. Rev., 112 (2012) 1196-1231.

[31] H.J. Choi, M.P. Suh, J. Am. Chem. Soc., 126 (2004) 15844-15851.

[32] G.J. Halder, C.J. Kepert, B. Moubaraki, K.S. Murray, J.D. Cashion, Science, 298 (2002) 17621765 .

[33] H. Sato, R. Matsuda, K. Sugimoto, M. Takata, S. Kitagawa, Nat. Mater.., 9 (2010) 661-666.

[34] S. Shimomura, M. Higuchi, R. Matsuda, K. Yoneda, Y. Hijikata, Y. Kubota, Y. Mita, J. Kim, M. Takata, S. Kitagawa, Nat. Chem., 2 (2010) 633-637.

[35] N. Yanai, K. Kitayama, Y. Hijikata, H. Sato, R. Matsuda, Y. Kubota, M. Takata, M. Mizuno, T. Uemura, S. Kitagawa, Nat. Mater.., 10 (2011) 787-793.

[36] K. Seki, S. Takamizawa, W. Mori, Chem. Lett., (2001) 332-333.

[37] R. Kitaura, F. Iwahori, R. Matsuda, S. Kitagawa, Y. Kubota, M. Takata, T.C. Kobayashi, Inorg. Chem., 43 (2004) 6522-6524.

[38] S. Furukawa, K. Hirai, K. Nakagawa, Y. Takashima, R. Matsuda, T. Tsuruoka, M. Kondo, R. Haruki, D. Tanaka, H. Sakamoto, S. Shimomura, O. Sakata, S. Kitagawa, Angew. Chem., Int. Ed., 48 (2009) 1766-1770.

[39] S.M.F. Lo, S.S.Y. Chui, L.Y. Shek, Z.Y. Lin, X.X. Zhang, G.H. Wen, I.D. Williams, J. Am. Chem. Soc., 122 (2000) 6293-6294.

[40] T. Uemura, Y. Ono, Y. Hijikata, S. Kitagawa, J. Am. Chem. Soc., 132 (2010) 4917-4924.

[41] L.P. Zhang, J.F. Ma, J. Yang, Y.Y. Pang, J.C. Ma, Inorg. Chem., 49 (2010) 1535-1550.

[42] B.L. Chen, C.D. Liang, J. Yang, D.S. Contreras, Y.L. Clancy, E.B. Lobkovsky, O.M. Yaghi, S.

Dai, Angew. Chem., Int. Ed., 45 (2006) 1390-1393.

[43] S.M. Chen, J.A. Zhang, C.Z. Lu, Crystengcomm, 9 (2007) 390-393.

[44] Z.X. Chen, S.C. Xiang, H.D. Arman, P. Li, D.Y. Zhao, B.L. Chen, Eur. J. Inorg. Chem., (2011) 2227-2231.

[45] Z.X. Chen, S.C. Xiang, D.Y. Zhao, B.L. Chen, Cryst. Growth Des., 9 (2009) 5293-5296. 
[46] M. Du, Z.H. Zhang, X.G. Wang, L.F. Tang, X.J. Zhao, Crystengcomm, 10 (2008) 1855-1865.

[47] D.N. Dybtsev, H. Chun, K. Kim, Angew. Chem., Int. Ed., 43 (2004) 5033-5036.

[48] S. Furukawa, K. Hirai, Y. Takashima, K. Nakagawa, M. Kondo, T. Tsuruoka, O. Sakata, S.

Kitagawa, Chem. Commun., (2009) 5097-5099.

[49] Q. Gao, Y.B. Xie, J.R. Li, D.Q. Yuan, A.A. Yakovenko, J.H. Sun, H.C. Zhou, Cryst. Growth Des., 12 (2012) 281-288.

[50] K.H. He, W.C. Song, Y.W. Li, Y.Q. Chen, X.H. Bu, Cryst. Growth Des., 12 (2012) 1064-1068.

[51] S. Henke, R.A. Fischer, J. Am. Chem. Soc., 133 (2011) 2064-2067.

[52] S. Henke, R. Schmid, J.-D. Grunwaldt, R.A. Fischer, Chem. Eur. J., 16 (2010) 14296-14306.

[53] S. Henke, A. Schneemann, A. Wutscher, R.A. Fischer, J. Am. Chem. Soc., 134 (2012) 9464-9474.

[54] K. Hirai, S. Furukawa, M. Kondo, M. Meilikhov, Y. Sakata, O. Sakata, S. Kitagawa, Chem.

Commun., 48 (2012) 6472-6474.

[55] K. Hirai, S. Furukawa, M. Kondo, H. Uehara, O. Sakata, S. Kitagawa, Angew. Chem., Int. Ed., 50 (2011) 8057-8061.

[56] Z. Hulvey, J.D. Furman, S.A. Turner, M. Tang, A.K. Cheetham, Cryst. Growth Des., 10 (2010) 2041-2043.

[57] H. Kim, D.G. Samsonenko, S. Das, G.H. Kim, H.S. Lee, D.N. Dybtsev, E.A. Berdonosova, K. Kim, Chem. Asia. J.., 4 (2009) 886-891.

[58] M. Kondo, Y. Takashima, J. Seo, S. Kitagawa, S. Furukawa, Crystengcomm, 12 (2010) 2350-2353.

[59] O. Kozachuk, K. Khaletskaya, M. Halbherr, A. Betard, M. Meilikhov, R.W. Seidel, B. Jee, A.

Poppl, R.A. Fischer, Eur. J. Inorg. Chem., (2012) 1688-1695.

[60] J.Y. Lee, D.H. Olson, L. Pan, T.J. Emge, J. Li, Adv. Funct. Mater., 17 (2007) 1255-1262.

[61] X.M. Li, Y.L. Niu, Q.W. Wang, B. Liu, Chin. J. Struct. Chem., 29 (2010) 1122-1126.

[62] X.M. Liu, L.H. Xie, J.B. Lin, R.B. Lin, J.P. Zhang, X.M. Chen, Dalton Trans., 40 (2011) 85498554.

[63] Y. Takashima, V.M. Martinez, S. Furukawa, M. Kondo, S. Shimomura, H. Uehara, M. Nakahama, K. Sugimoto, S. Kitagawa, Nat. Commun., 2 (2011).

[64] Y.X. Tan, Y.P. He, J. Zhang, Inorg. Chem., 50 (2011) 11527-11531.

[65] D. Tanaka, S. Horike, S. Kitagawa, M. Ohba, M. Hasegawa, Y. Ozawa, K. Toriumi, Chem. Commun., (2007) 3142-3144.

[66] K. Uemura, F. Onishi, Y. Yamasaki, H. Kita, J. Solid State Chem., 182 (2009) 2852-2857.

[67] K. Uemura, Y. Yamasaki, Y. Komagawa, K. Tanaka, H. Kita, Angew. Chem., Int. Ed., 46 (2007) 6662-6665.

[68] M.M. Dubinin, Chem. Rev., 60 (1960) 235-241. 
[69] E. Nishibori, M. Takata, K. Kato, M. Sakata, Y. Kubota, S. Aoyagi, Y. Kuroiwa, M. Yamakata, N. Ikeda, J. Phys. Chem. Solid, 62 (2001) 2095-2098.

[70] K. Kato, R. Hirose, M. Takemoto, S. Ha, J. Kim, M. Higuchi, R. Matsuda, S. Kitagawa, M. Takata, AIP Conf. Proc. 1234 (2010) 875-878.

[71] A. Boultif, D. Louer, J. Appl. Cryst., 24 (1991) 987-993.

[72] B. LeBail, H. Duroy, J.L. Fourquet, Mat. Res. Bull., 23 (1988) 447-452.

[73] H.M. Rietveld, J. Appl. Cryst., 2 (1969) 65-71.

[74] F. Izumi, T. Ikeda, Mater. Sci. Forum, 198 (2000) 321-324.

[75] The dabco ligand disorderes at theree position therefore we can see 24 carbon atoms in each one dabco molecule in the crystal structures.

[76] The cross section of the channels are not strictly square but for simplicity, those are denoted by a

product of width and height, named as aperture, sa, sb, and sc , for the channels running parallel to the a, $\mathrm{b}$ and c-axis, respectively.

[77] D.W. Breck, Zeolite Molecular Sieves, Wiley \& Sons, New York, 1984.

[78] K. Kaneko, K. Murata, Adsorption, 3 (1997) 197-208.

[79] W. Steele, Chem. Rev., 93 (1993) 2355-2378.

[80] M. Jaroniec, K.P. Gadkaree, L. Choma, Colloids and Surfaces A, 118 (1996) 203-210. 
Figure(s)

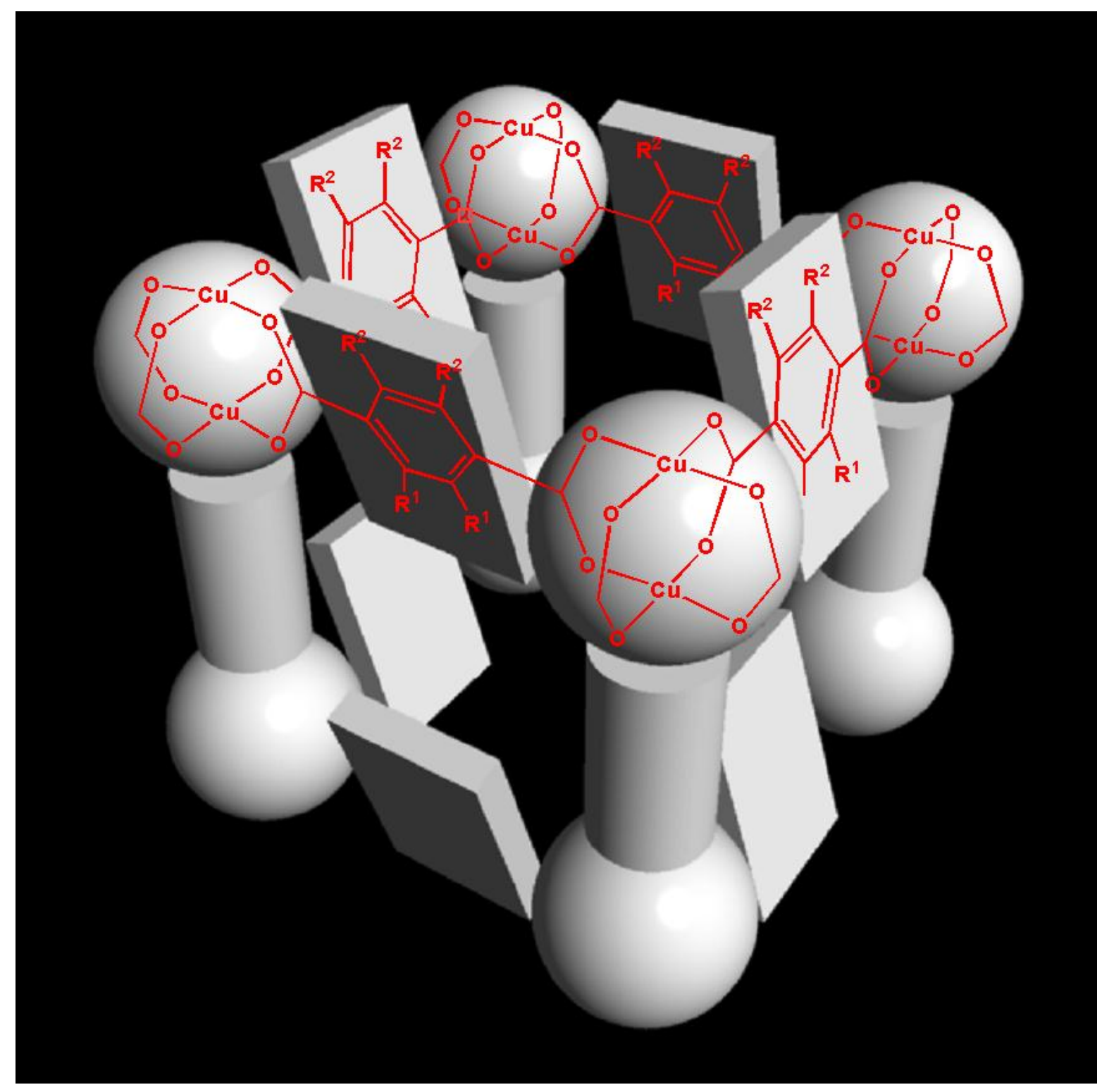

Scheme 1. Representation of the "phenylene fin" in a microporous coordination polymer. 

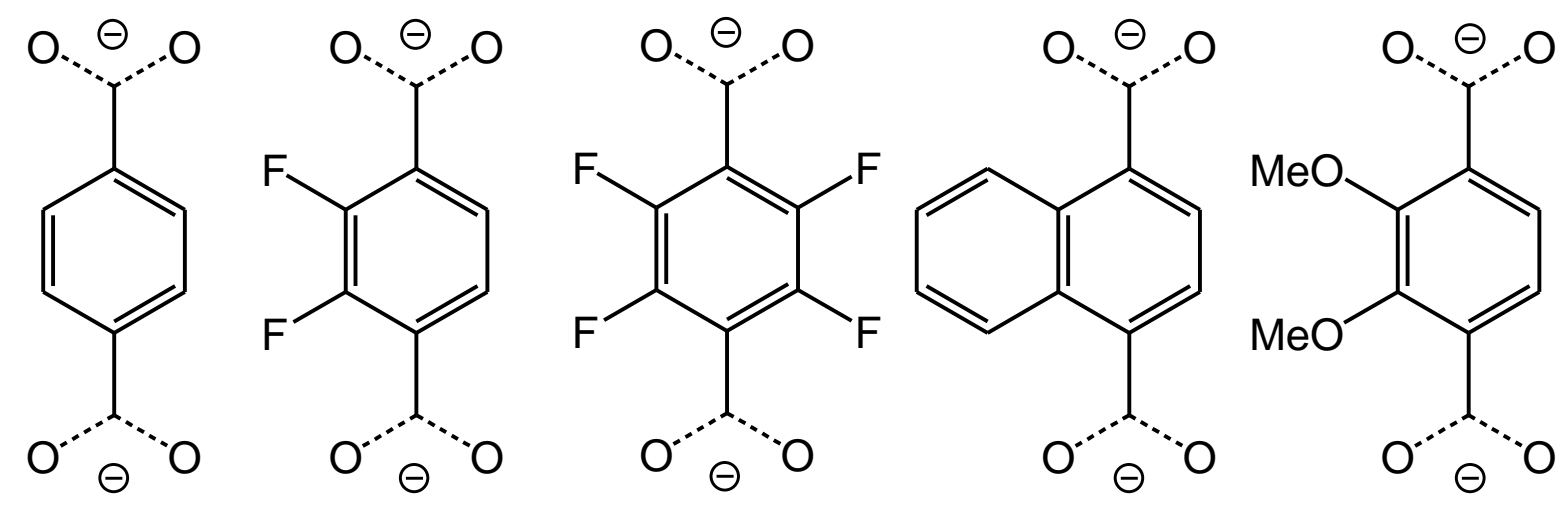

BDC DFBDC

TFBDC

Scheme 2. Terephthalate family as a fin.

NDC

DMBDC 

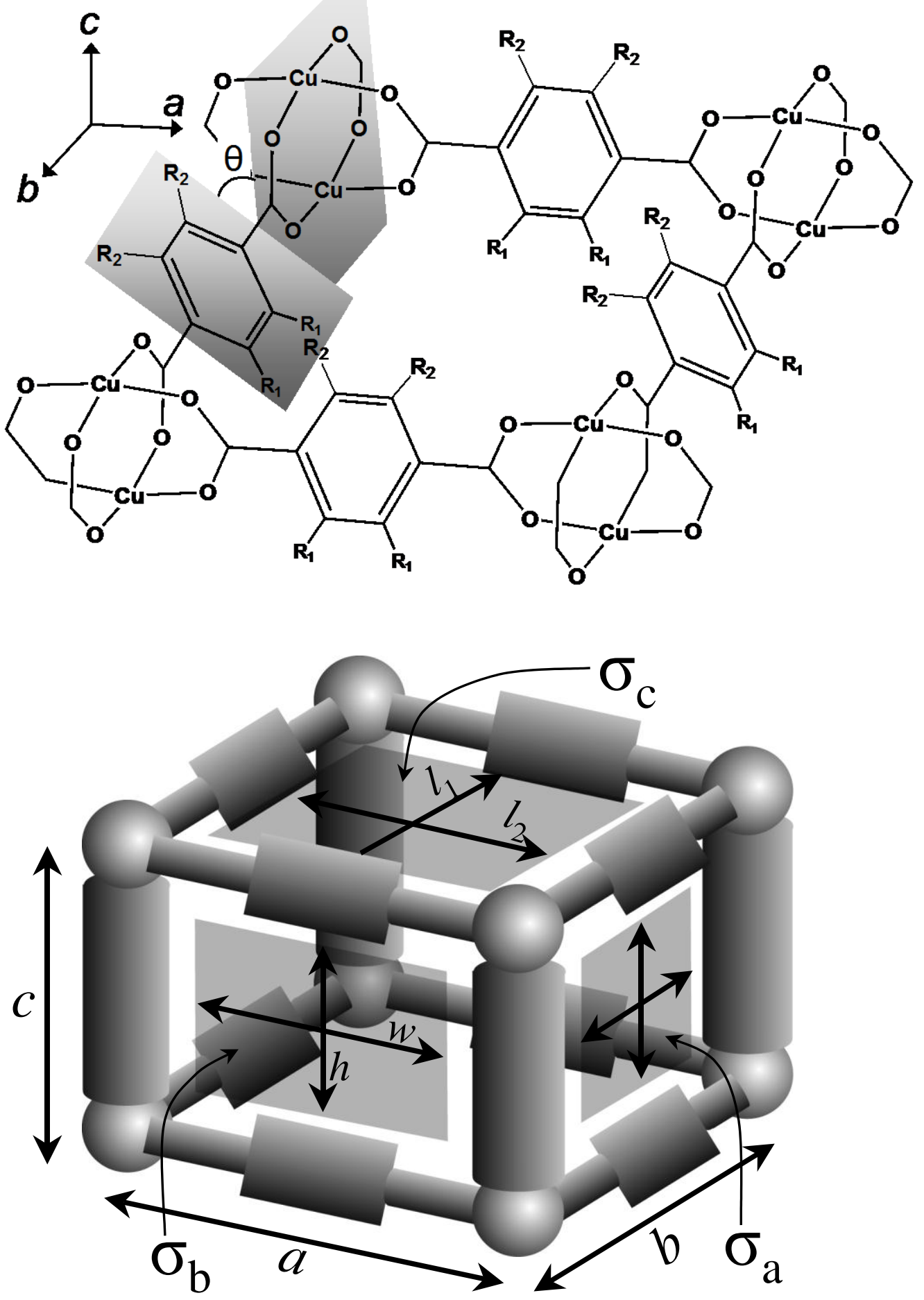

Scheme 3. A schematic representation of the JAST's framework. 


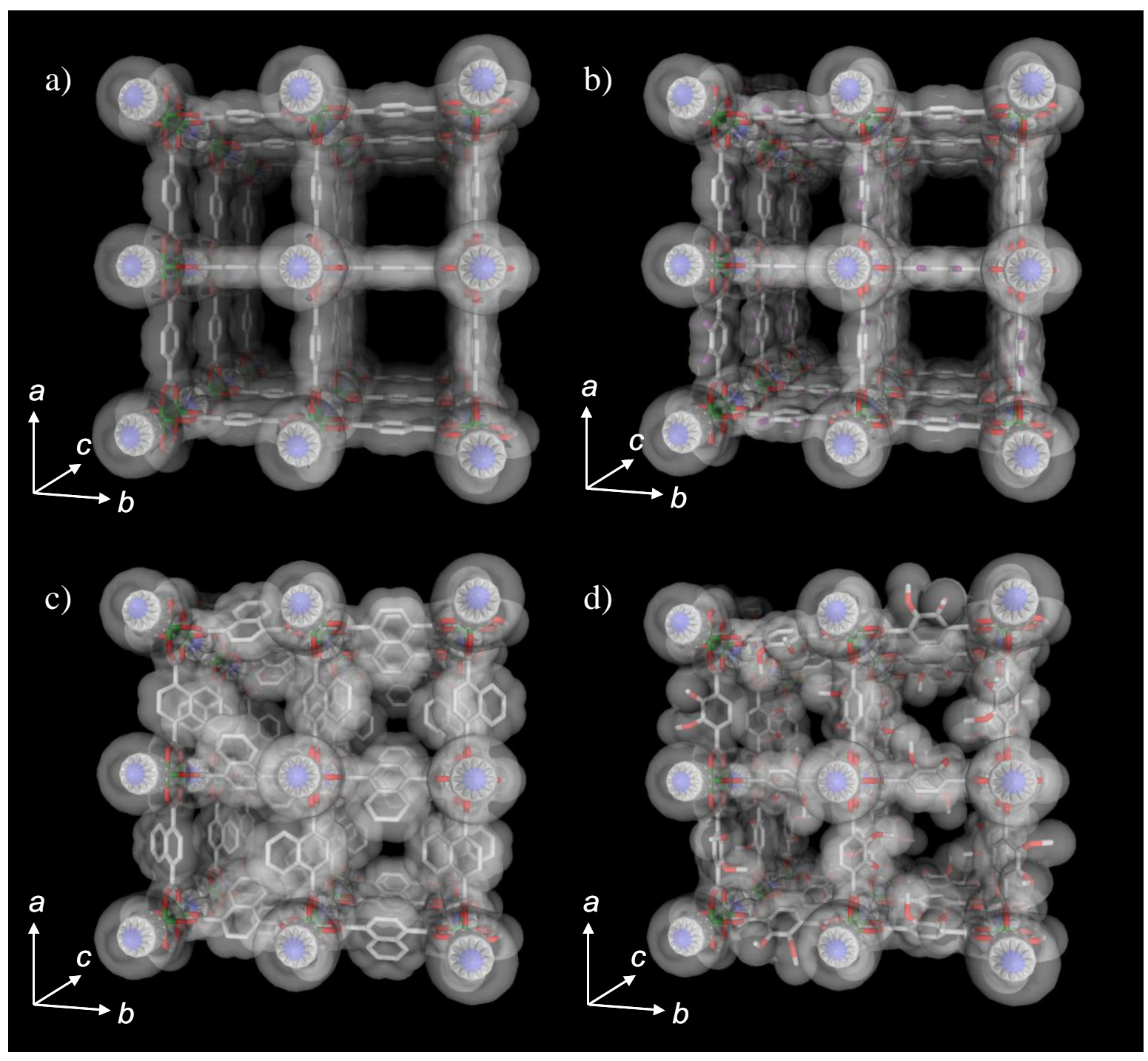

Figure 1. Crystal structures of a) JAST-1, b) JAST-2, c) JAST-4 and d) JAST-5. All of them are represented by the perspective views down from the $a$ axis, displayed by stick and van der Waals surface models. ( $\mathrm{Cu}$, green; $\mathrm{O}$, red; $\mathrm{N}$, blue; $\mathrm{C}$, gray) Hydrogen atoms and the disordering atoms in the phenylene planes are omitted for clarity. 


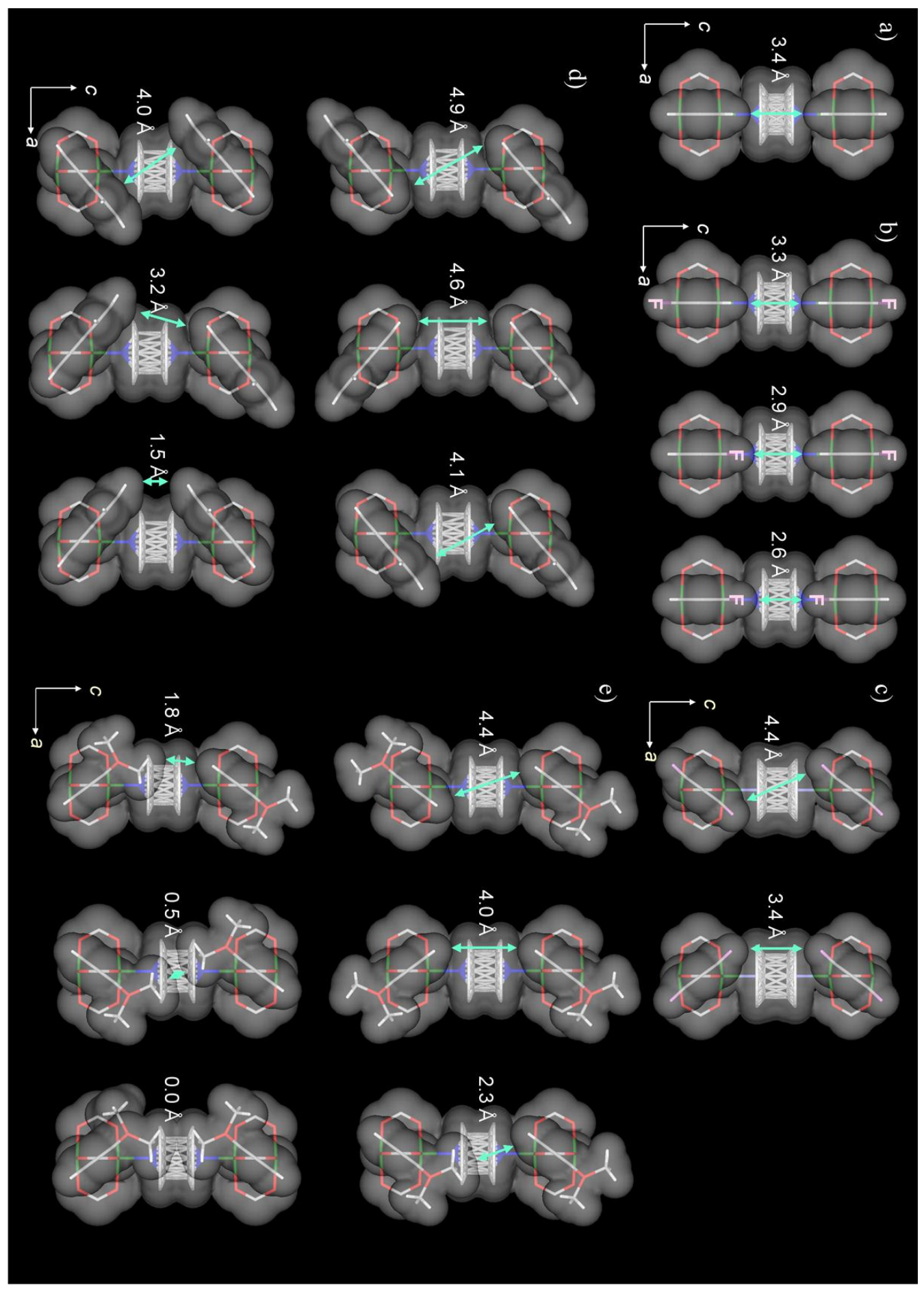

Figure 2. Cross sections on the $a c$ plane of the channels along the $a$ axis for a) JAST-1, b) JAST-2, c) JAST-3, d) JAST-4 and e) JAST-5. The aperture of the channels is defined by the value of $h$ (blue arrows), depending on the tilt angle and symmetry of the phenylene moiety. The same situation is obtained for the channels along the $b$ axis. All the structural views are displayed by stick and van der Waals surface models. $(\mathrm{Cu}$, green; $\mathrm{O}$, red; $\mathrm{N}$, blue; $\mathrm{C}$, gray; F, pink) 


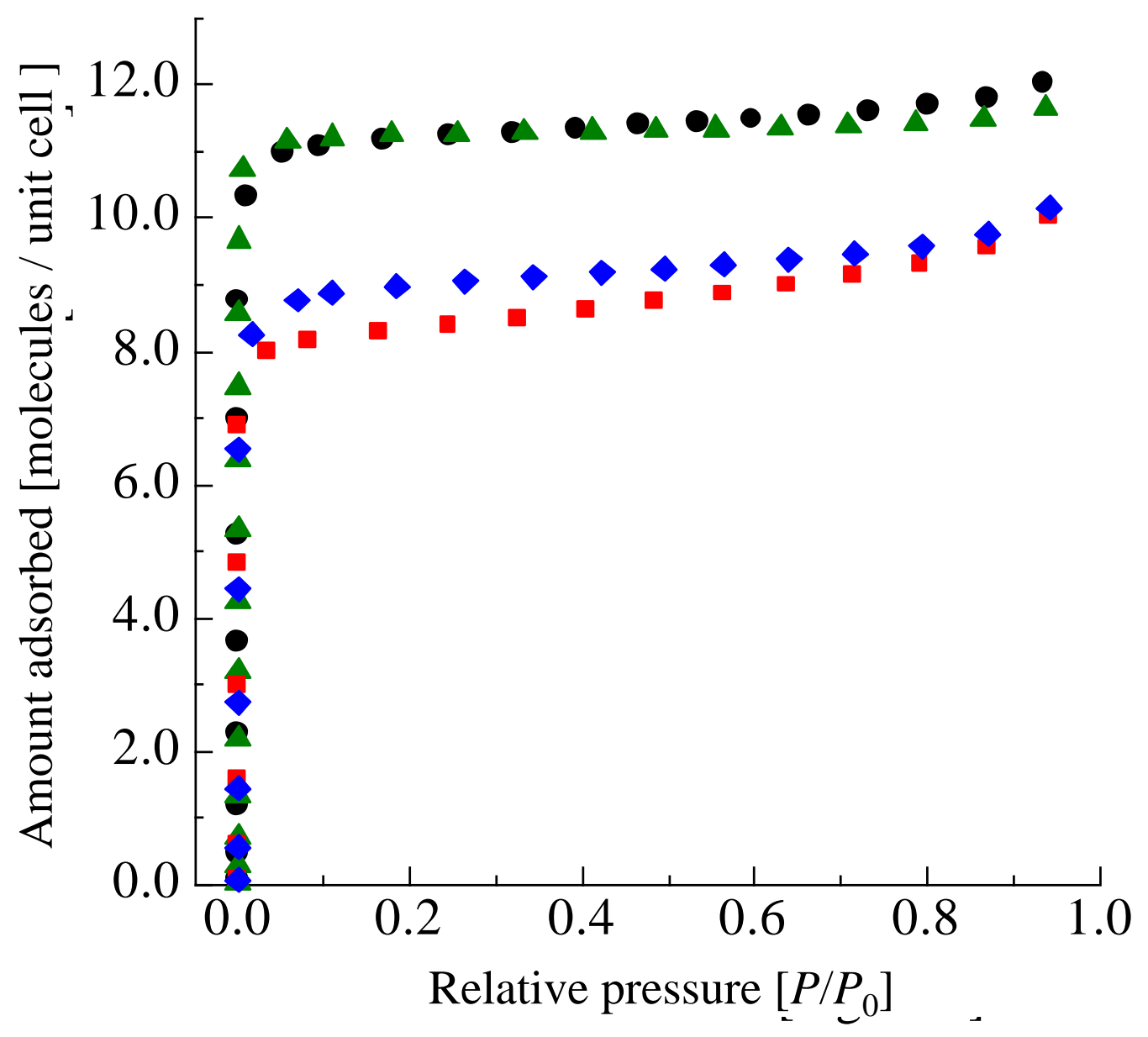

Figure 3. Adsorption isotherms for nitrogen of JAST-1 (black, O), -2 (green, $\Delta$ ), -4 (red, $\square$ ) and $\mathbf{- 5}$ (blue, ) at $77 \mathrm{~K} . P / P_{0}$ is the relative pressure, where $P_{0}$ is the saturated vapor pressure, $101 \mathrm{kPa}$, of nitrogen at $77 \mathrm{~K}$. 


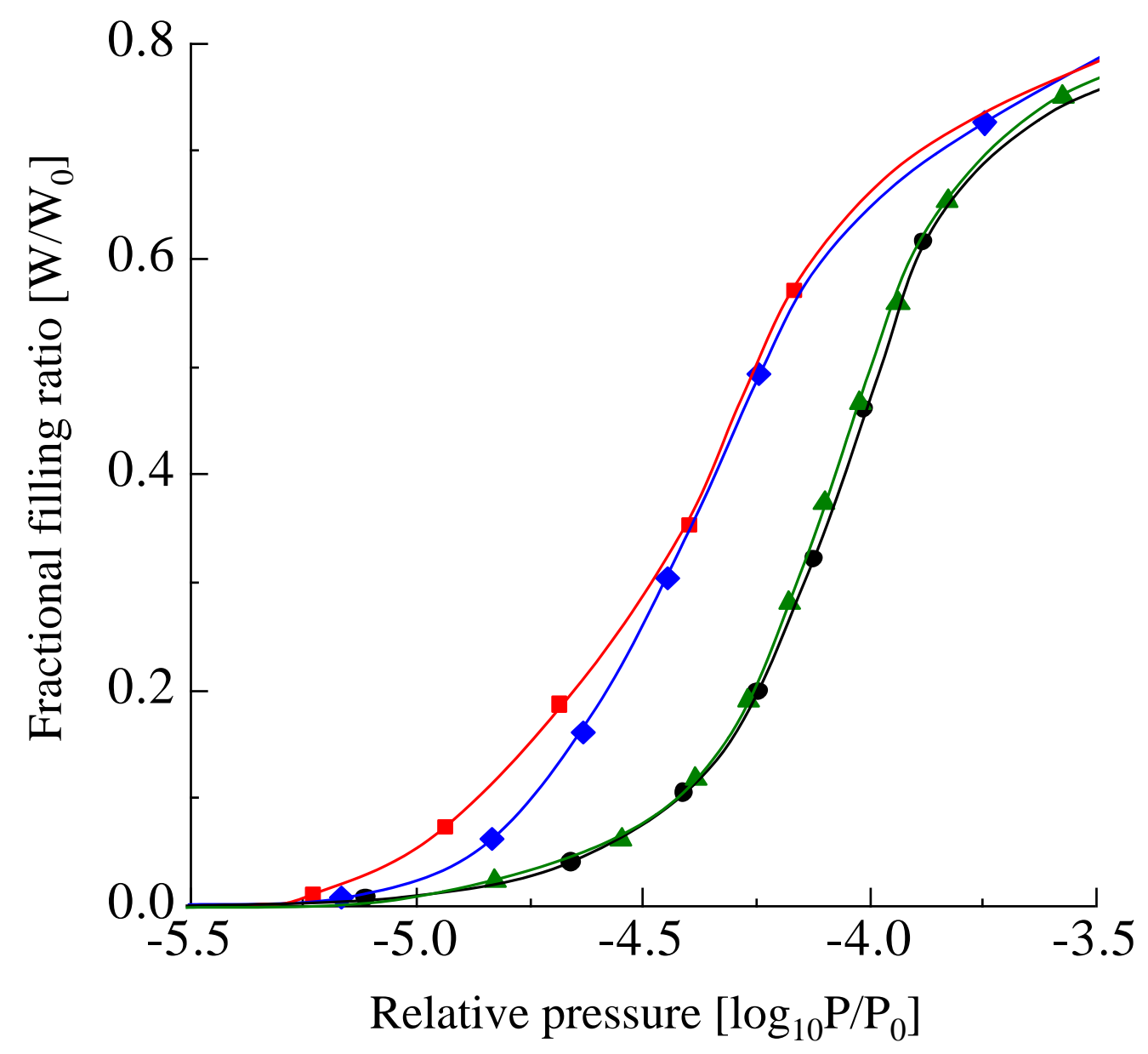

Figure 4. Adsorption isotherms for lower pressure resion for nitrogen of JAST-1 (black, O), 2 (green, $\Delta$ ), $\mathbf{- 4}\left(\right.$ red, $\square$ ) and $\mathbf{- 5}$ (blue, $\diamond$ ) at $77 \mathrm{~K} . W / W_{0}$ and $P / P_{0}$ is the fractional filling ratio in the pore and relative pressure, respectively, where $W$ and $W_{0}$ is the amount adsorbed and saturated amount adsorbed, respectively, and $P_{0}$ is the saturated vapor pressure, $101 \mathrm{kPa}$, of nitrogen at $77 \mathrm{~K}$. 


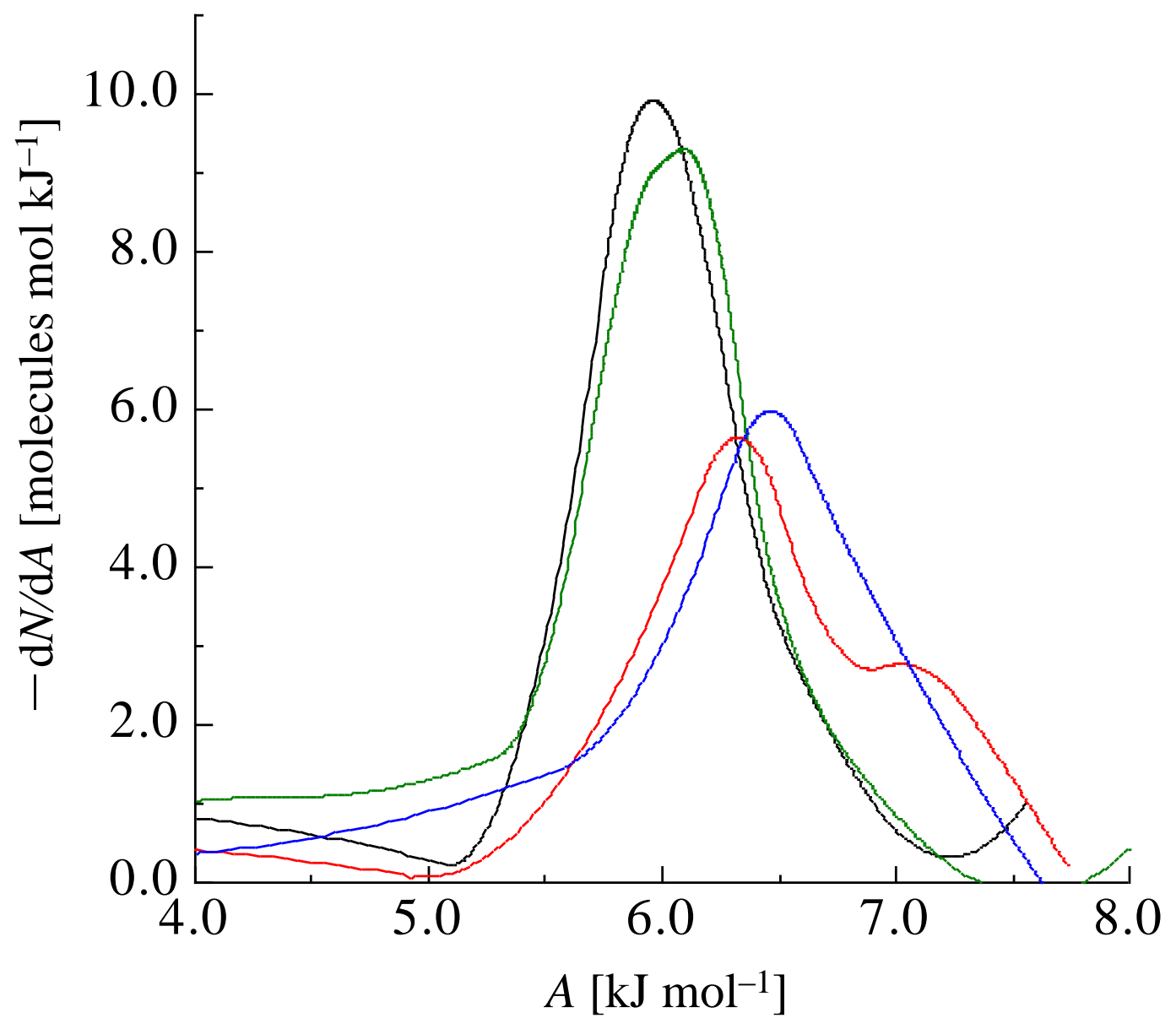

Figure 5. Adsorption potential distributions for JAST-1 (black line), -2 (green line), -4 (red line) and -5 (blue line), where $A$ is Polanyi's adsorption potential and $N$ is the number of molecules adsorbed in each unit pore. 


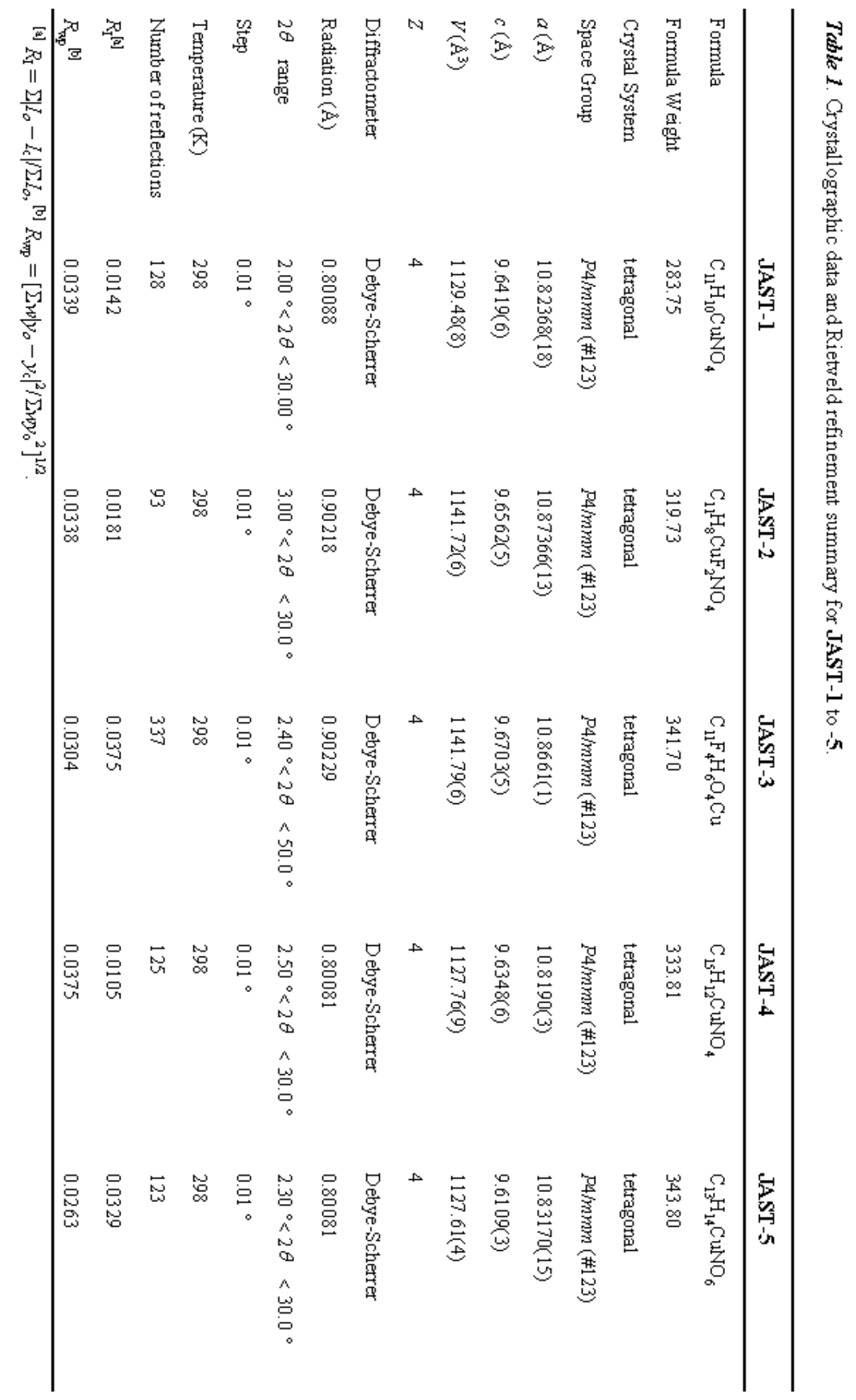


Table 2: Classification Based on the Relative Position of Phenylene Motifs of JAST Compounds.

\begin{tabular}{c|ccccc}
\hline & JAST-1 & JAST-2 & JAST-3 & JAST-4 & JAST-5 \\
\hline Dihedral angle $[\theta]\left(^{\circ}\right)$ & 0 & 0 & 36 & 49 & 36 \\
Ligand symmetry ${ }^{[\mathrm{a}]}$ & $\mathrm{S}$ & $\mathrm{A}$ & $\mathrm{S}$ & $\mathrm{A}$ & $\mathrm{A}$ \\
size $^{[\mathrm{b}]}$ of $\sigma_{\mathrm{c}}\left(\AA^{2}\right)$ & $7.9 \times 7.9$ & $7.9 \times 7.9$ & $5.3 \times 5.3$ & $2.4 \times 2.4$ & $2.5 \times 2.5$ \\
size $^{[\mathrm{b}]}$ of $h^{[\mathrm{c}]} \sigma_{\mathrm{a}}$ or $\sigma_{\mathrm{b}}$ & 3.4 & 2.6 & 3.4 & $5.7 \times 5.7$ & $6.4 \times 6.4$ \\
$(\AA)$ & & 3.3 & 4.4 & 4.9 & 0.0 \\
\hline
\end{tabular}

[a] Symbols "S" and "A" denote "symmetrical" and "asymmetrical", respectively.

${ }^{[b]}$ The upper and lower data show the minimum and maximum dimension, respectively, because of their distribution, whose modes are partly shown in Figure 2 and Figure S5

${ }^{[c]}$ In the case of $\sigma_{\mathrm{a}}$ or $\sigma_{\mathrm{b}}$, the width $(w)$ is common as $4.7 \AA$, and therefore, the only length is listed. 
Table 3: Micropore and Thermodynamic Parameters of JAST Compounds by Nitrogen Adsorptions ${ }^{[a]}$

\begin{tabular}{c|ccccc}
\hline complexes & $\begin{array}{c}W_{0} \\
\left(\mathrm{~cm}^{-3}(\mathrm{stp}) / \mathrm{g}\right)\end{array}$ & $\begin{array}{c}N_{0} \\
(\text { molecules } / \\
\text { unit pore })\end{array}$ & $\begin{array}{c}V m \\
\left(\mathrm{~cm}^{-3} / \mathrm{g}\right)\end{array}$ & $\begin{array}{c}\beta E o \\
(\mathrm{~kJ} / \mathrm{mol})\end{array}$ & $\begin{array}{c}q_{s t, \Phi=1 / e} \\
(\mathrm{~kJ} / \mathrm{mol})\end{array}$ \\
\hline JAST-1 & 472 & 11.9 & 0.73 & 9.8 & 15.4 \\
JAST-2 & 400 & 11.4 & 0.62 & 11.3 & 16.8 \\
JAST-4 & 283 & 8.4 & 0.44 & 10.6 & 16.2 \\
JAST-5 & 294 & 9.0 & 0.46 & 9.7 & 15.3 \\
\hline
\end{tabular}

[a] Obtained from Dubinin-Radushkevich analysis 
Graphical abstract

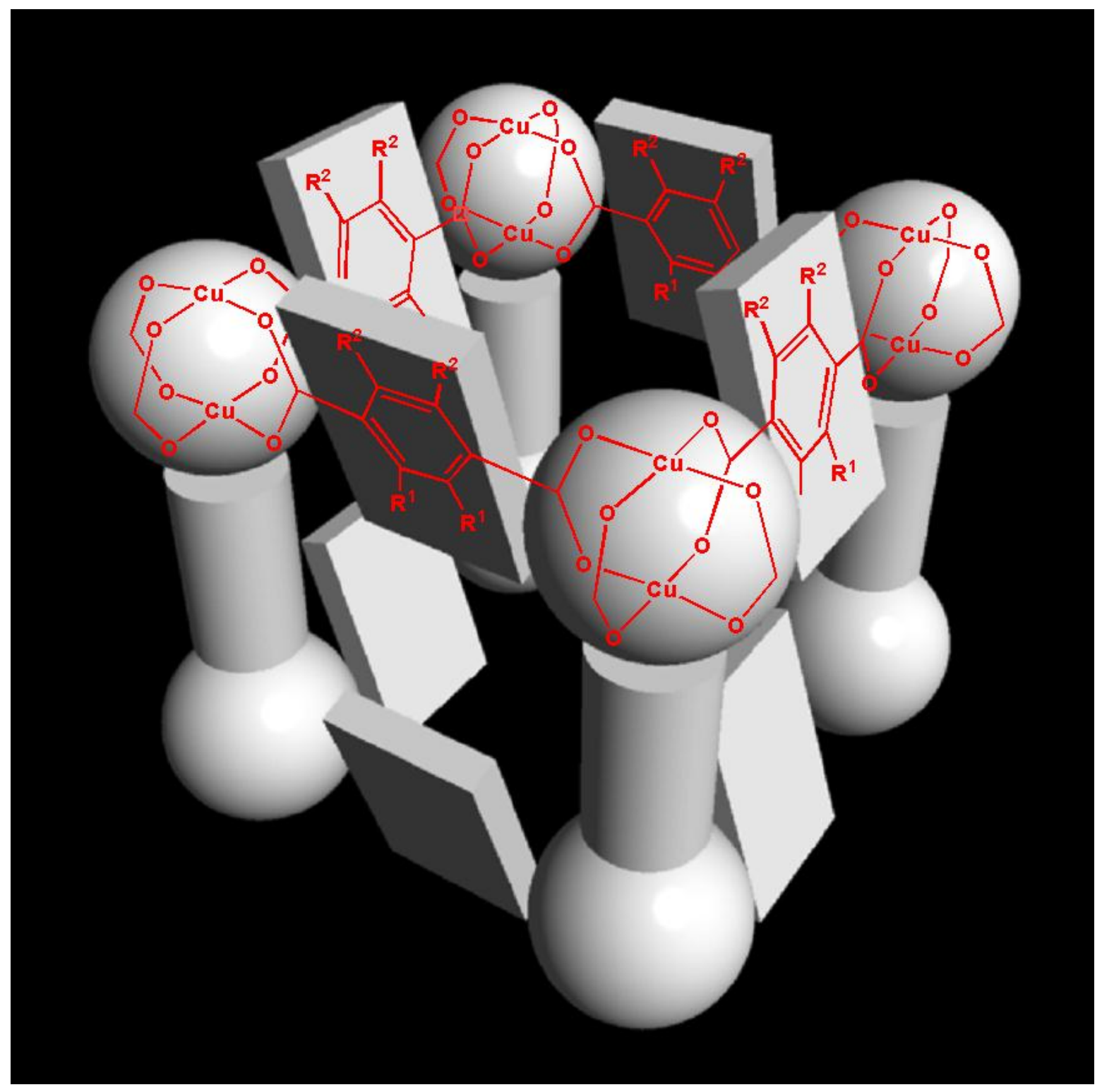

